\title{
Structural rearrangements detected in newly-formed hexaploid tritordeum after three sequential FISH experiments with repetitive DNA sequences
}

\author{
SANDRA CABO $^{1}$, ANA CARVALHO ${ }^{1}$, ANTÓNIO MARTÍN ${ }^{2}$ and JOSÉ LIMA-BRITO ${ }^{1 *}$ \\ ${ }^{1}$ Institute of Biotechnology and Bioengineering (IBB), Centre of Genomics and Biotechnology (CGB), \\ University of Tras-os-Montes and Alto Douro (UTAD), P.O. Box 1013, 5001-801 VilaReal, Portugal \\ ${ }^{2}$ Instituto de Agricultura Sostenible (IAS), Consejo Superior de Investigaciones Cientificas (CSIC), Apartado 4084, \\ 14080 Córdoba, España
}

[Cabo S., Carvalho A., Martín A. and Lima-Brito J. 2014 Structural rearrangements detected in newly-formed hexaploid tritordeum after three sequential FISH experiments with repetitive DNA sequences. $J$. Genet. 93, 183-188]

\section{Introduction}

Mitotic chromosomes of tritordeum $\left(\mathrm{H}^{\text {ch }} \mathrm{H}^{\text {ch }} \mathrm{AABB}\right.$; $2 n=6 x=42$; HT27) and their respective parents, Hordeum chilense L. $\left(\mathrm{H}^{\text {ch }} \mathrm{H}^{\text {ch }} ; 2 n=2 x=14 ; \mathrm{H} 7\right)$ and Triticum turgidum (AABB; $2 n=4 x=28$; T81), were analysed after three sequential fluorescence in situ hybridization (FISH) experiments performed with six probes: the simple sequence repeats (SSRs) $(\mathrm{AG})_{10}$ and $(\mathrm{AAC})_{5}$; genomic DNA from H. chilense; 45S rDNA (pTa71); 5S rDNA (pTa794); and $\mathrm{pSc} 119.2$, to achieve a comparative analysis about the distribution of these sequences in the three plant materials. The SSR $(A G)_{10}$ probe showed eight hybridization signals on tritordeum chromosomes and six in the chromosomes of its male parent (durum wheat). No hybridization signals were detected in female parent $H$. chilense. Two additional FISH experiments were carried out regarding the discrimination of the parental genomes in HT27 and the identification of the individual chromosomes showing the $(\mathrm{AG})_{10}$ hybridization signals in both HT27 and durum wheat line T81. Based on the comparative analyses among the hybridization patterns observed in tritordeum and durum wheat, we proposed a sequence of structural rearrangements to explain the origin of an additional $(\mathrm{AG})_{10}$ hybridization signal in the newlyformed allopolyploid (tritordeum) that was absent in its male parent (durum wheat). These results enabled new insights about cereal genome evolution.

Tritordeum, as well as triticale, are synthetic amphiploids belonging to the Triticeae tribe which present agronomic interest (Martín et al. 1996). Allopolyploidization

\footnotetext{
*For correspondence. E-mail: jbrito@utad.pt.
}

constitutes a revolutionary event because a new species arises in a single step, as a result of hybridization of two or more divergent genomes in a single nucleus and polyploidization due to genome duplication (Ozkan et al. 2001). In response to such events, the genomes of allopolyploid species undergo irreversible reorganizations and genome modifications (Ozkan et al. 2001), which might include: structural rearrangements in chromosomes (Leitch and Bennett 1997) or DNA sequences (Song et al. 1995; Wendel et al. 1995); alterations in the regulation of gene expression (Comai et al. 2000); transposon activation (Matzke and Matzke 1998); amplification, segregation or elimination of DNA sequences that could be highly repetitive (Salina et al. 2000) or low-copy number (Feldman et al. 1997; Liu et al. 1998). Ozkan et al. (2001) reported the fast elimination of noncoding sequences with low-copy number in newly-formed allopolyploids involving the Aegilops and Triticum genera, which were present in their diploid parental species. The elimination of these sequences promotes strict bivalent pairing (avoiding intergenomic recombinations), high fertility and heterosis (Ozkan et al. 2001). Nonetheless, previous cytogenetic studies of pollen mother cells (PMCs) at metaphase I developed by our research group in tetraploid tritordeum and $\mathrm{F}_{1}$ interspecific hybrids involving hexaploid tritordeum as parent, demonstrated intragenomic and homeologous chromosome pairing by the occurrence of wheat multivalents (Carvalho et al. 2005; Lima-Brito et al. 2006), without jeopardizing their fertility.

ND-FISH technique constitutes one variant of the conventional FISH which does not involve the denaturation of chromosomal DNA, is more cost-effective, less laborious and faster than conventional FISH, once the hybridization and the

Keywords. fluorescence in situ hybridization; nondenaturing FISH; simple sequence repeats; structural rearrangements; tritordeum; wheat; multicolour FISH. 
posthybridization washes could be performed in one single day (Cuadrado and Jouve 2010). These authors considered that ND-FISH is more suitable for SSR probes and when the chromosome spreads have to be reprobed several times.

The SSRs or microsatellites have been widely used as probes in FISH in cereals (Bardsley et al. 1999; Castilho et al. 2000; Cuadrado et al. 2000). SSR probes constitute valuable tools as cytogenetic markers in cereals. Their use could provide the identification of individual chromosomes; the efficient detection of variation among different taxa; and their physical distribution and abundance gives insights about genome organization and evolution (Schmidt et al. 1993; Depeiges et al. 1995; Cuadrado and Schwarzacher 1998), thus being useful for the study of genomic restructuration in newly-formed allopolyploids.

In the present study, we analysed mitotic chromosome spreads of tritordeum, recently produced by interspecific crosses between the $H$. chilense line $\mathrm{H} 7$ and the $T$. turgidum line T81 using FISH experiments with repetitive DNA sequences as probes, including SSRs, to compare their hybridization patterns and probable occurrence of genomic restructuring in the newly-formed allopolyploid.

\section{Materials and methods}

The line HT27 of hexaploid tritordeum $\left(\mathrm{H}^{\mathrm{ch}} \mathrm{H}^{\mathrm{ch}} \mathrm{AABB}\right.$; $2 n=42$ ) was produced by interspecific crosses between the female parent $H$. chilense (line $\mathrm{H} 7 ; \mathrm{H}^{\mathrm{ch}} \mathrm{H}^{\mathrm{ch}} ; 2 n=2 x=14$ ) and the male parent durum wheat (line T81; AABB; $2 n=4 x=28$ ). Seeds from these three plant materials were allowed to germinate in distilled water in the dark at $25^{\circ} \mathrm{C}$. Root tips with about $1.5 \mathrm{~cm}$ were collected, treated on icecold water for $24 \mathrm{~h}$ and fixed in ethanol:acetic acid (3:1), until the preparation of chromosome spreads by squashing.

The SSR probes $(\mathrm{AG})_{10}$ and $(\mathrm{AAC})_{5}$ were labelled by the Random Primed DNA Labelling kit (Roche Applied Science, Mannheim, Germany) with biotin-16-dUTP (Roche Applied Science) and 50\% biotin and 50\% digoxigenin11-dUTP (Roche Applied Science), respectively. The SSR $(\mathrm{AG})_{10}$ probe was used alone following the ND-FISH protocol described by Cuadrado and Jouve (2010). The genomic DNA from $H$. chilense and 45S rDNA sequence - pTa71 (Gerlach and Bedbrook 1979) were labelled with biotin and digoxigenin, respectively, using the Nick Translation kit (Roche Applied Science). The cloned repetitive DNA sequences pSc119.2 (McIntyre et al. 1990) and 5S rDNA were labelled with biotin and digoxigenin, respectively, by PCR as described by Schwarzacher and Heslop-Harrison (2000).

The genomic DNA of $H$. chilense and pTa71 were used simultaneously on a conventional FISH protocol as described by Schwarzacher and Heslop-Harrison (2000), and in the presence of unlabelled sheared genomic DNA from durum wheat to act as blocking DNA. This protocol was also applied to the multicolour FISH which was performed with three probes in simultaneous, namely, the 5S rDNA, pSc119.2 and SSR (AAC) 5 , to avoid further reprobes of the same chromosome spreads.

We used the antibodies fluorescein-avidin (Vector Laboratories, Peterborough, UK) and Anti-Digoxigenin-Rhodamine (Roche Applied Science) for probes labelled with biotin and digoxigenin, respectively. After counterstaining the chromosomes with DAPI (Vector Laboratories), the hybridization signals were observed on the Epifluorescence microscope AxioPlan2 (Zeiss, Göttingen, Germany). Images were captured by a digital camera (AxioCam, Zeiss) using the AxionVision 3.2 software, and after double or triple exposure with appropriate filters, were prepared for printing with Adobe Photoshop 6.0 (http://www.adobe.com).

Individual chromosomes were identified by comparison of the hybridization patterns achieved during this study with ideograms previously reported (Mukai et al. 1990, 1991, 1993).

\section{Results and discussion}

The ND-FISH technique was successful in detection of clear and intense hybridization signals of the SSR $(A G)_{10}$ probe on the mitotic chromosomes of tritordeum line HT27 and respective male parent-durum wheat line T81 (figures $1 \& 2$ ). No hybridization signals were observed on the $H$. chilense chromosome spreads. The observation of secondary constrictions in four chromosomes allowed the preliminary identification of the chromosome pairs $1 \mathrm{~B}$ and $6 \mathrm{~B}$ in tritordeum and durum wheat (figure $1, \mathrm{a} \& \mathrm{~b}$ ). The SSR (AG) $)_{10}$ probe showed eight hybridization signals in tritordeum, located in four chromosome pairs, including the nucleolar ones $1 \mathrm{~B}$ and $6 \mathrm{~B}$, and on two unknown pairs. The physical location of the $\operatorname{SSR}(A G)_{10}$ probe was pericentromeric, centromeric and subtelomeric in both plant materials (figures 1, a\&d). However, in the metaphase cells of durum wheat, we found only six hybridization signals, located in three chromosome pairs, one of them being the pair 6B, metacentric chromosomes with a secondary constriction (figure 1d). To identify unequivocally the nucleolar chromosomes in both plant materials, and the origin-species of the chromosomes with hybridization of the $(A G)_{10}$ probe in tritordeum, we carried out a conventional FISH experiment using genomic DNA from $H$. chilense and/or pTa71 as probes (figure 1, b\&e).

All mitotic metaphases of tritordeum (line HT27) showed $14 H$. chilense (green) chromosomes and 28 wheat chromosomes (blue) (figure 1b) after conventional FISH revealing the success of the interspecific crosses made at CSIC (Spain). The simultaneous use of pTa71 in tritordeum allowed the identification of four nucleolar chromosome pairs: $5 \mathrm{H}^{\mathrm{ch}}$, $6 \mathrm{H}^{\mathrm{ch}}, 1 \mathrm{~B}$ and $6 \mathrm{~B}$ (figure $1 \mathrm{~b}$ ). The pTa71 also identified the chromosome pairs $1 \mathrm{~B}$ and $6 \mathrm{~B}$ in durum wheat (figure 1e). The number and physical location of the SSR (AG) 10 probe in tritordeum and durum wheat chromosomes were 


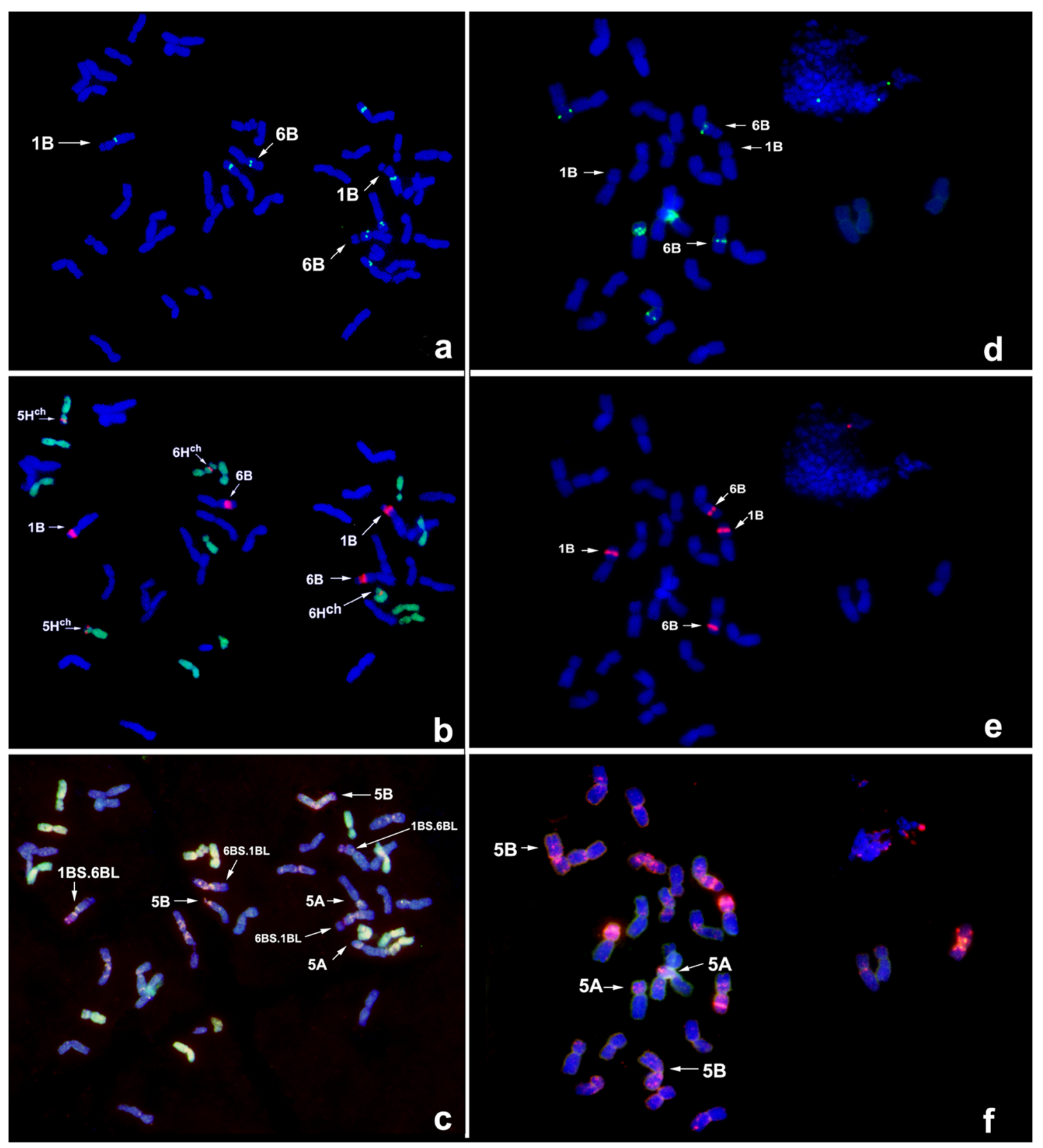

Figure 1. Mitotic metaphase cells of tritordeum line HT27 $\left(\mathrm{H}^{\mathrm{ch}} \mathrm{H}^{\mathrm{ch}} \mathrm{AABB} ; 2 n=42\right)(\mathrm{a}, \mathrm{b}, \mathrm{c})$ and durum wheat line T81 $(\mathrm{AABB} ; 2 n=4 x=$ 28) (d, e, f) after: (a, d) ND-FISH with the probe SSR (AG) 10 (green), showing eight hybridization signals in HT27 (a) and six hybridization signals in durum wheat (d), and allowing the preliminary identification of the nucleolar chromosomes based on their shape and position of secondary constrictions; (b, e) conventional FISH performed with genomic DNA of $H$. chilense (green) and pTa71 (red), simultaneously, as probes, enabling the discrimination of the parental genomes. The pTa71 probe identified eight nucleolar chromosomes (arrows) in HT27 (b) and four in durum wheat (e); (c, f) multicolour FISH performed with the probes pSc119.2 (green); (AAC) 5 (yellow) and 5S rDNA (red), simultaneously, providing the identification of the individual chromosomes 5A and 5B in HT27 (c) and T81 (f), as well as the 1B and 6B chromosomes derived from structural rearrangements that occurred during the allopolyploidization, as being the $6 \mathrm{BS} .1 \mathrm{BL}$ and $1 \mathrm{BS} .6 \mathrm{BL}$ chromosome pairs (arrows) in HT27 (c).

confirmed after the analysis of 20 metaphase cells per plant, and five plants per plant material. No polymorphic distribution of the SSR (AG) 10 was found among tritordeum or durum wheat plants. Despite the easy identification of the nucleolar chromosomes $1 \mathrm{~B}$ and $6 \mathrm{~B}$ based on their primary and secondary constrictions position in durum wheat and tritordeum (figure $1, \mathrm{a}, \mathrm{b}, \mathrm{d} \& \mathrm{e}$ ), the remaining two chromosome pairs with hybridization signals of SSR $(A G)_{10}$ could not be identified with the first two FISH experiments. Besides, an explanation was needed for the existence of an additional SSR (AG) 10 -enriched region on the $1 \mathrm{~B}$ chromosome of tritordeum that was absent in its male parent (durum wheat). Thus, we performed a multicolour FISH using 5S rDNA, pSc119.2 and SSR (AAC) 
probes, simultaneously, to identify the unknown chromosome pairs with the hybridization signal $(A G)_{10}$, and to infer about putative structural rearrangements in the origin of the additional SSR-enriched region on the 1B chromosome of the allopolyploid. The hybridization signals of the pSc119.2 were more intense in tritordeum than in durum wheat, probably masked by the intense hybridization of the SSR (AAC) 5 probe (figure 1, c\&f). The hybridization patterns of the $5 \mathrm{~S}$ rDNA and $\mathrm{pSc} 119.2$ probes permitted the identification of the $5 \mathrm{~A}$ and $5 \mathrm{~B}$ chromosome pairs (figure 1, c\&f). The SSR (AAC) 5 probe allowed the detection of probable structural rearrangements within the chromosome $6 \mathrm{~B}$, which after recombination events involving the chromosome $1 \mathrm{~B}$, could be in the origin of the additional $(A G)_{10}$ signal in the chromosome 1B of tritordeum (figure 2c). Both SSR regions seem to have coincidental locations on the chromosomes identified here (see figure 2c). Figure 2c presents a schematic representation of three putative events of structural rearrangements which resulted on the hybridization patterns of the SSR $(\mathrm{AG})_{10}$ probe visualized in tritordeum (figure 1a). Therefore, based on the hybridization patterns of the repetitive DNA sequences used in this study, the wheat 6B chromosome probably experienced an inverted pericentric duplication which induced two SSR $(A G)_{10}$ regions in its pericentromeric region (one in the short and other in the long arm). This resultant chromosome, considered as a derivative $6 \mathrm{~B}-\operatorname{der}(6 \mathrm{~B})$ chromosome, then recombined with the wheat $1 \mathrm{~B}$ chromosome, due to homeologous
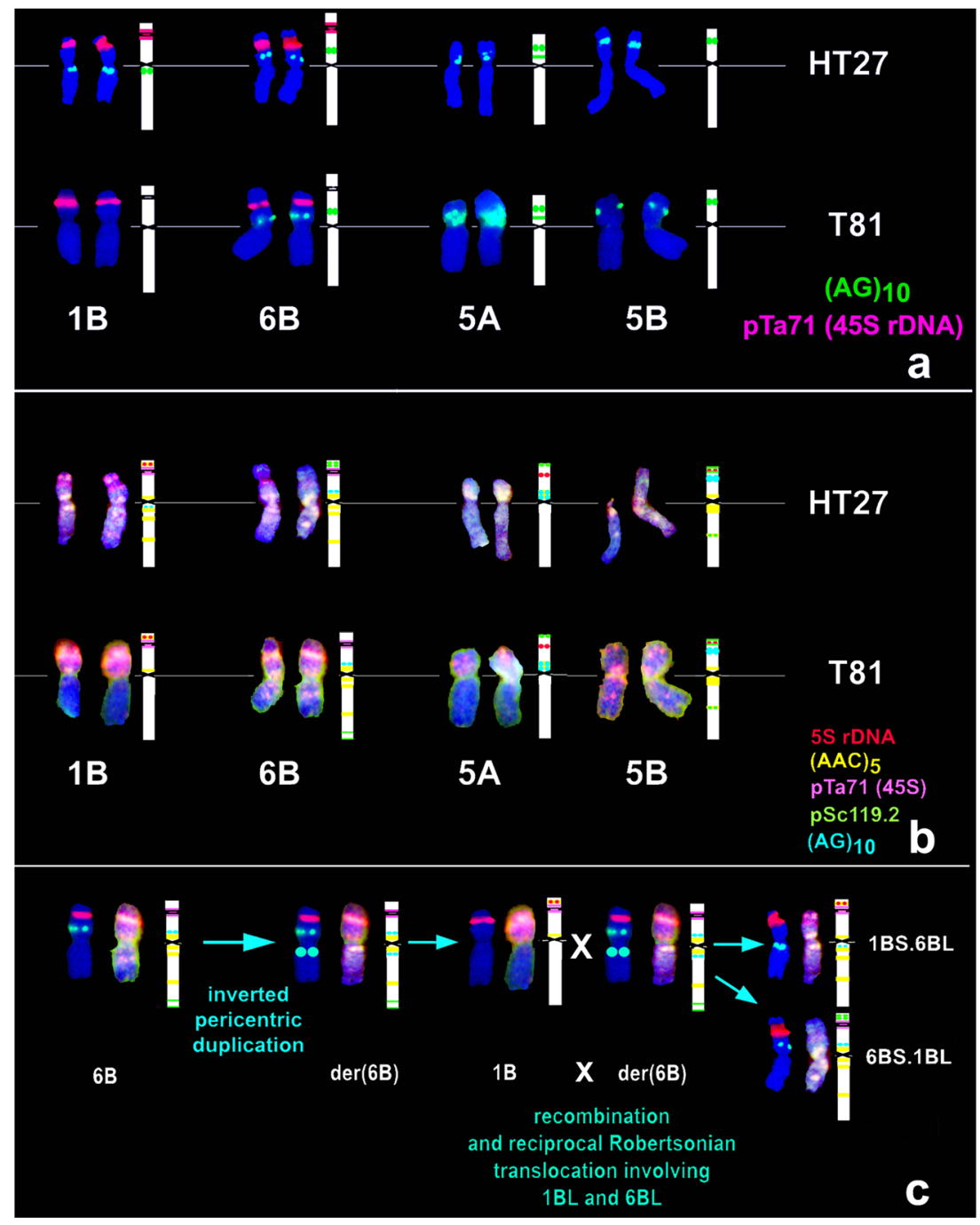

Figure 2. (a) Ideogram of tritordeum (HT27) and durum wheat (T81) chromosomes displaying the physical location of the SSR (AG) 10 (green) and pTa71 (red) probes after ND-FISH and FISH, respectively. The 1B chromosome of durum wheat did not show hybridization signal for (AG) 10 . (b) Ideogram of the same chromosomes in tritordeum (HT27) and durum wheat (T81) displaying the physical location of the probes: 5S rDNA (red), (AAC) 5 (yellow), pTa71 (pink); pSc119.2 (green) and (AG) 10 (blue) after ND-FISH, FISH and multicolour FISH. These patterns allowed the identification of the chromosomes $5 \mathrm{~A}$ and $5 \mathrm{~B}$ in both plant materials. (c) Schematic representation of structural rearrangements involving the $1 \mathrm{~B}$ and $6 \mathrm{~B}$ chromosomes of $\mathrm{T} 81$ which could be in the origin of the physical location of $(\mathrm{AG})_{10}$ in the $1 \mathrm{~B}$ chromosome of HT27. After careful analysis of all hybridization patterns, and considering the proposed events of rearrangements, the chromosomes formerly identified as 1B and 6B in HT27 (a, b) were then assigned as being 1BS.6BL and 6BS.1BL (c). 
chromosome pairing, resulting in a reciprocal Robertsonian translocation which produced two pairs of chromosomes, namely, 1BS.6BL and 6BS.1BL (figures 1c and 2c). These assumptions derived from additional results such as the lack of two signals for the pSc119.2 probe in the wheat 1BL chromosome, which appears on the satellite region of the tritordeum 6B chromosome (identified as 6BS.1BL) (figure 2, $\mathrm{b} \& \mathrm{c})$. Further, the physical association of the SSR regions $(\mathrm{AAC})_{5}$ to the $(\mathrm{AG})_{10}$ in the pericentromeric, centromeric and subtelomeric regions might be in the origin of additional structural rearrangements mediated by retrotransposons, such as the pericentric duplication reported here, due to insertion mechanisms. In addition, we recently detected polymorphic $(\mathrm{AAC})_{5}$ patterns among nucleolar chromosomes of different bread wheat cultivars and we suggested the putative involvement of retrotransposons in the origin of that polymorphism due to their close association with SSR regions (Carvalho et al. 2013).

Most pericentromeric regions of eukaryotic chromosomes are heterochromatic and are the most rapidly evolving regions of complex genomes. The closely related genomes within hexaploid wheat ( $T$. aestivum L., $2 n=6 x=42$, AABBDD), as well as in the related Triticeae taxa, share large conserved chromosome segments and provide a good model for the study of the evolution of pericentromeric regions (Qi et al. 2006). These authors also reinforce the idea that $\mathrm{B}$ wheat chromosomes are more prone to structural rearrangements than those from A and D genomes. Our previous studies have confirmed this assumption as different translocations or rearrangements always involve wheat B chromosomes (A. Carvalho, H. Guedes-Pinto and J. LimaBrito, unpublished data; Carvalho et al. 2013). The occurrence of wheat multivalents in tetraploid tritordeum and in $\mathrm{F}_{1}$ interspecific hybrids from the Triticeae tribe and involving tritordeum as parent (Carvalho et al. 2005; Lima-Brito et al. 2006) supported the probable intragenomic recombination by homeologous pairing between wheat chromosomes. Other spontaneous translocations previously detected by our group consisted of the presence of two rDNA loci in the same wheat chromosome, which was identified as $1 \mathrm{BS} .6 \mathrm{BS}$ in one $\mathrm{F}_{1}$ interspecific hybrid (AABBDH ${ }^{\mathrm{ch}}$ ) produced from crosses between the Portuguese bread wheat cultivar 'Barbela' and tritordeum (A. Carvalho, H. Guedes-Pinto and J. Lima-Brito, unpublished data). Later, we also detected the spontaneous translocation 7BS/7RL in one $\mathrm{F}_{1}$ interspecific hybrid (AABBRH ${ }^{\mathrm{ch}}$ ) (Carvalho et al. 2009). Recently, Carvalho et al. (2013) detected, after NDFISH performed with the SSR probe $(\mathrm{AAC})_{5}$, polymorphic patterns among nucleolar chromosomes of different bread wheat cultivars, and among bread and durum wheat cultivars. Therefore, the use of SSR probes in FISH experiments for the study of cereals could provide new insights about genomic restructuring among allopolyploids (Carvalho et al. 2013) but also among newly-formed allopolyploids and respective parental species, contributing for the study of genomes evolution. According to Cuadrado and Jouve
(2010), ND-FISH technique is suitable for SSR probes, and once it does not involves denaturing. The chromosome morphology is well maintained, being important for successive reprobing on the same slide. In this study, ND-FISH was successful once it allowed the detection of the hybridization signals of the SSR $(\mathrm{AG})_{10}$ probe, and enable two additional sequential hybridizations by conventional FISH (involving formamide and denaturing temperatures). However, we also demonstrated that the SSR (AAC) 5 probe could also be used with the conventional FISH protocol given the successful hybridization observed here, even in the presence of two other probes, simultaneously (multicolour). Globally, the three FISH protocols performed with a total of six probes allowed the identification of six chromosome pairs: $1 \mathrm{~B}, 6 \mathrm{~B}$, $5 \mathrm{H}^{\mathrm{ch}}, 6 \mathrm{H}^{\mathrm{ch}}, 5 \mathrm{~A}$ and $5 \mathrm{~B}$, and of two rearranged wheat chromosome pairs in tritordeum, namely, 6BS.1BL and 1BS.6BL (figures 1, c\&f, 2). The newly-formed tritordeum HT27 line experienced fast structural rearrangements relatively to its male parent which involved the two major nucleolar wheat chromosomes. Considering our previous studies, we have already detected enriched-SSR regions in 1B and 6B wheat nucleolar chromosomes, we are confident that the persistent study of SSRs organization in cereals from the Triticeae tribe which involve wheat, might probably clarify the evolution of the $\mathrm{B}$ genome. Considering our previous and these present results, the $1 \mathrm{~B}$ and $6 \mathrm{~B}$ chromosomes seem to be highly variable and prone to recombination at their pericentromeric and subtelomeric regions. Therefore, the occurrence of several structural rearrangements in the wheat B genome over million of years could be the reason why the donor species of this genome are as yet unidentified.

\section{Acknowledgements}

This work was partially supported by the HY-WHEAT project, International Consortium (P-KBBE/AGRGPL/0002/2010), funded by COMPETE, QREN, EU and the Portuguese Foundation for Science and the Technology (FCT).

\section{References}

Bardsley D., Cuadrado A., Jack P., Harrison G., Castilho A. and Heslop-Harrison J. S. 1999 Chromosome markers in the tetraploid wheat Aegilops ventricosa analysed by in situ hybridization. Theor. Appl. Genet. 99, 300-304.

Carvalho A., Guedes-Pinto H., Martín A., Heslop-Harrison P. and Lima-Brito J. 2005 Genome discrimination and chromosome pairing in the Hordeum chilense $\times$ Aegilops tauschii amphiploid. Euphytica 144, 85-89.

Carvalho A., Martín A., Heslop-Harrison J. S., Guedes-Pinto H. and Lima-Brito J. 2009 Identification of the spontaneous 7BS/7RL intergenomic translocation in one F1 multigeneric hybrid from the Triticeae tribe. Plant Breeding 128, 105-108.

Carvalho A., Guedes-Pinto H. and Lima-Brito J. 2013 Polymorphism of the simple sequence repeat (AAC) $)_{5}$ in the nucleolar chromosomes of Old Portuguese wheat cultivars. J. Genet. 92, $583-586$. 
Castilho A., Vershinin A. and Heslop-Harrison J. S. 2000 Repetitive DNA and the chromosomes in the genome of oil palm (Elaeis guineensis). Ann. Bot. 85, 837-844.

Comai L., Tyagi A. P., Winter K., Holmes-Davis R., Reynolds S. H., Stevens Y. and Byers B 2000 Phenotypic instability and rapid gene silencing in newly formed Arabidopsis allotetraploids. Plant Cell 12, 1551-1567.

Cuadrado A. and Schwarzacher T. 1998 The chromosomal organization of simple sequence repeats in wheat and rye genomes. Chromosoma 107, 587-594.

Cuadrado A. and Jouve N. 2010 Chromosomal detection of simple sequence repeats (SSRs) using nondenaturing FISH (ND-FISH). Chromosoma 119, 495-503.

Cuadrado A., Schwarzacher T. and Jouve N. 2000 Identification of different chromatin classes in wheat using in situ hybridization with simple sequence repeat oligonucleotides. Theor. Appl. Genet. 101, 711-717.

Depeiges A., Goubely C., Lenoir A., Cocherel S., Picard G., Raynal M. et al. 1995 Identification of the most represented repeated motifs in Arabidopsis thaliana microsatellite loci. Theor. Appl. Genet 91, 160-168.

Feldman M., Liu B., Segal G., Abbo S., Levy A. A. and Vega J. M 1997 Rapid elimination of low-copy DNA sequences in polyploid wheat: a possible mechanism for differentiation of homoeologous chromosomes. Genetics 147, 1381-1387.

Gerlach W. L. and Bedbrook J. R. 1979 Cloning and characterization of ribosomal RNA genes from wheat and barley. Nucleic Acids Res. 7, 1869-1885.

Leitch I. J. and Bennett M. D. 1997 Polyploidy in angiosperms. Trends Plant Sci. 2, 470-476.

Lima-Brito J., Carvalho A., Martin A., Heslop-Harrison J. S. and Guedes-Pinto H. 2006 Morphological, yield, cytological and molecular characterization of a breed wheat $\times$ tritordeum $F_{1}$ hybrid. J. Genet. 85, 123-131.

Liu B., Vega J. M., Segal G., Abbo S., Rodova M. and Feldman M. 1998 Rapid genomic changes in newly synthesized amphiploids of Triticum and Aegilops. I. Changes in low-copy non-coding DNA sequences. Genome 41, 272-277.

Martín A., Martinez-Araque C., Rubiales D. and Ballesteros J. 1996 Tritordeum: triticale's new brother cereal. In Triticale: today and tomorrow (ed. H. Guedes-Pinto, N. Darvey and V. P. Carnide), pp. 57-72. Kluwer Academic Publishers, The Netherlands.
Matzke M. A. and Matzke A. J. M 1998 Polyploidy and transposons. Trends Ecol. Evol. 13, 241.

McIntyre C. L., Pereira S., Moran L. B. and Appels R. 1990 New Secale cereale (rye) DNA derivatives for the detection of rye chromosome segments in wheat. Genome 33, 635-640.

Mukai Y., Endo T. R. and Gill B. S. 1990 Physical mapping of the 5S rRNA multigene family in common wheat. J. Hered. 81, 290295.

Mukai Y., Endo T. R. and Gill B. S. 1991 Physical mapping of the 18S.26S rRNA multigene family in common wheat: identification of a new locus. Chromosoma 100, 71-78.

Mukai Y., Nakahara Y. and Yamamoto M. 1993 Simultaneous discrimination of the three genomes in hexaploid wheat by multicolour fluorescence in situ hybridization using total genomic and highly repeated DNA probes. Genome 36, 489-494.

Ozkan H., Levy A. and Feldman M. 2001 Allopolyploidy - induced rapid genome evolution in the wheat (Aegilops-Triticum) group. Plant Cell 13, 1735-1747.

Qi L., Friebe B. and Gill B. S. 2006 Complex genome rearrangements reveal evolutionary dynamics of pericentromeric regions in the Triticeae. Genome 49, 1628-1639.

Salina E. A., Ozkan H., Feldman M. and Shumny V. K. 2000 Subtelomeric repeat reorganization in synthesized wheat amphiploids. In Proceedings of the Conference on Biodiversity and Dynamics of Ecosystems in North Eurasia (ed. N. Kolchanov and D. Furman), pp. 102-105. Institute of Cytology and Genetics Press, Novosibirsk, Russia.

Schmidt T., Boblenz K., Metzlaff M., Kaemmer D., Weising K. and Kahl G. 1993 DNA fingerprinting in sugar beet (Beta vulgaris) identification of double-haploid breeding lines. Theor. Appl. Genet. 85, 653-657.

Schwarzacher T. and Heslop-Harrison J. S. 2000 Practical in situ hybridisation. Oxford BIOS, Scientific Publishers, UK.

Song K., Lu P., Tang K. and Osborn T. C. 1995 Rapid genome change in synthetic polyploids of Brassica and its implications for polyploid evolution. Trends Ecol. Evol. 9, 348-352.

Wendel J. F., Schnabel A. and Seelanan T. 1995 Bidirectional interlocus concerted evolution following allopolyploid speciation in cotton (Gossypium). Proc. Natl. Acad. Sci. USA 92, 280-284. 